\title{
Growing Together with Indonesian SIGCHI
}

On May 19, 2014, the Indonesian SIGCHI chapter was born. Like all babies, this chapter was not born instantly. The idea was conceived back in early 2002, when we started our work in HCI in Indonesia. Many still considered HCI an alien concept from the West at that time. In order to grow awareness, we held a series of informational events for academics and professionals in the region.

In 2011, we saw a light at the end of the tunnel when Adi Tedjasaputra received an invitation from Zhengjie Liu, adjunct chair for developing worlds at SIGCHI, to attend the SIGCHI Asia workshop in Beijing. I represented Adi at the event, and suddenly a new hope arose. During the event, attended by many ACM SIGCHI chairs and representatives from Asian countries, we were informed how ACM SIGCHI could support developing countries in nurturing the field of HCI.

After reviewing the readiness of the market, Adi and I approached ACM SIGCHI at the end of 2013 about advancing HCI and UX in Indonesia with their support. It was indeed the right timing - they accepted our proposal to support a special kick-off event. UX Indonesia-Malaysia 2014 was held on April 26, 2014, in Jakarta as the first-ever UX conference conducted in Indonesia. The event was attended by academics, practitioners, and students from a variety of affiliations in Indonesia and Malaysia and featured renowned speakers from Indonesia, Malaysia, China, Australia, and the U.S. This first HCI/UX venue opened our eyes to a significant commitment to keeping the flame alight in the wider community. There had been an increase in people working in HCI/UX in Indonesia and Malaysia, yet many of us still worked in silos.

After the conference, we invited several people to be part of the process of forming a new chapter. Our eventual proposal to ACM to form Indonesia ACM SIGCHI was approved on May 19,2014 . What a joy to have reached this milestone!

Indonesia ACM SIGCHI is a unique chapter, as it covers the whole nation of Indonesia, the fourth most populated country in the world. To run this giant chapter, we seeded the development of local representatives. At the moment, there are six local representatives that work on the specific needs of the community in their own regions. This concept seems to work well, as we have been developing and executing diverse ideas and programs from each region. Since its formation, this local chapter has been active, conducting seminars, bootcamps, and workshops to promote both ACM SIGCHI and the fields of $\mathrm{HCI} / \mathrm{UX}$ in Indonesia. We hope this chapter will continue to grow and have a greater impact. We look forward to seeing you all at CHIuXID 2015 (April 8-10, 2015; http://chiuxindo. uxindo.com/chi-ux-indonesia-2015/)!

(1) Eunice Sari

$\rightarrow$ eunice.saridacm.org

(1) Adi Tedjasaputra

$\rightarrow$ aditaacm.org

(c) Tuomo Kujala

$\rightarrow$ sigchi-vp-chaptersdacm.org

chiuxindo.uxindo.com

르 facebook.com/groups/chiuxindo

a aindonesia_ux

\section{Indonesia ACM SIGCHI is a unique chapter, as it covers the whole nation of Indonesia, the fourth most populated country in the world.}

